\title{
Comparative Study on Analysis and Designing of Post- Tensioned Flat Slab Vs Conventional Slab
}

\author{
Soubhagya Ranjan Rath ${ }^{1}$, Susanta Kumar Sethy ${ }^{2}$ Mukesh Kumar Dubey ${ }^{3}$ \\ ${ }^{1}$ Student M. Tech Structure, ${ }^{2}$ Assistant Professor, ${ }^{3}$ Associate Professor, Civil Engineering department, \\ University of Petroleum and Energy Studies, Dehradun, India
}

\begin{abstract}
Importance of skyscrapers or high rise buildings in the present scenario is increasing. Building using conventional slabs are diminished due to its inefficiency as per tall structures and long spans. To overcome this many other types of the slab has been considered for the improvement and workability of structures, in which flat slab and post-tensioned slab are very much popular among the construction of tall structures. It will be much more effective to combine post-tensioned slab and flat slab than usual slabs. These types of slabs also have advantages over conventional as they provide an aesthetic view for commercial or residential projects in recent projects such as high-rise structures and long-range frames as they are safe as per design. By doing the comparative analysis and design of post-tensioned flat slab with a conventional slab, we can show how beneficial will be the process of making PT flat slab than other slabs.
\end{abstract}

Keywords:- Analytical parameters, Design parameters, PT flat slab, RCC conventional slab, ETABS, SAFE, Efficiency, $\quad$ Economical comparison

\section{INTRODUCTION:-}

Multi-story buildings should be designed for commercial and residential purposes in such a way that they can sustain more load than that desired for the purpose of safety. Post-tensioning system is probably the latest discovery in man's ongoing search for new materials and methods of construction. The concept of pre-stressing is used to express the mechanism for introducing internal stresses in a concrete or masonry element during construction to counteract the external loads applied when the structure can be used.

PT slab:- Typically, post-tensioned (PT) slabs are flat slabs, band beams, and slabs or ribbed slabs. PT slabs offer the finest type of slab as concrete is processed to its strengths, mainly kept in compression. Because of the pre-stress, which can also be used to counteract deflections for longer spans can be achieved.

PT tendons generally being used in 2 types. These are -

\section{Banded tendons}

\section{Uniform/Distributed tendons}

Banded tendons:- Tendons which are placed narrow to each other and placed each at the midspan and column strips.
Uniform/Distributed tendons:- Tendons which are equally placed to each other and distributed along that direction throughout the slab.

\section{LITERATURE REVIEW:-}

Considering the basic flat slab benefits we can say its provision of clear ceiling heights is greater, ease of formwork and hence not costly, flat ceiling gives the attractive appearance or aesthetic view to the structure, drop panel is provided instead of beams above column \& gives better illumination. In the case of the post-tensioned slab, a certain factored amount of dead load was performed, which is between $60 \%-80 \%$. the flat slab also has few drawbacks like longer span should not more than 2.2 times shorter span, super-imposed flat slab load shall not exceed 3 times dead load design, the slab thickness requirement is higher in a flat slab case and the slab thickness should exceed $125 \mathrm{~mm}$. It is not flexible compared to conventional slab beam column structure and less seismic resistant. On the other type of slab-like PT slabs, the benefits of having PT tendons are those slabs often more costeffective for spans over 6 to 6.7 meters long. Concrete quantity reductions of up to one fourth i.e. $25 \%$, and typical rebar of up to $65 \%$. Shoring and shelling can be removed in this case as soon as the tendons are stressed or tensed. This reduces the building period by making the lower floor access faster, detailed post-tensioned slab construction results in lower permeability and lower cracking, the span length of up to 9 meters is commonly used for 2-way PT slab systems that allow flexible tenant spacing and better viewing lines, building net dead load and lateral strength resistance 
structure that includes shear walls, columns and foundations is less due to thinner and lighter posttensioned slabs.

\section{METHODOLOGY:-}

Considering a ongoing project for the comparison of different types of slab. The following are the steps which has been followed for this comparative research for slabs:-

1. Model of the Multi-storey tall structure has been created in ETABS as per architectural layout.

2. Defined materials and concrete sections including core walls and slabs.

3. Assigned load cases and other parameters to the model.

4. Analysed the structure and calculated the storey response graph for both type of slabs in different cases and compared it.

5. For the detailed slab analysis and design comparison, it has been imported to SAFE software.

6. Assigning and checking for slab properties, load cases and design parameters for different types of slabs including Post tensioned tendons.

7. The slab models have been analysed and designed for further parametric comparison in case of PT flat slab, conventional and even for normal flat slab.

\section{MODELS:-}

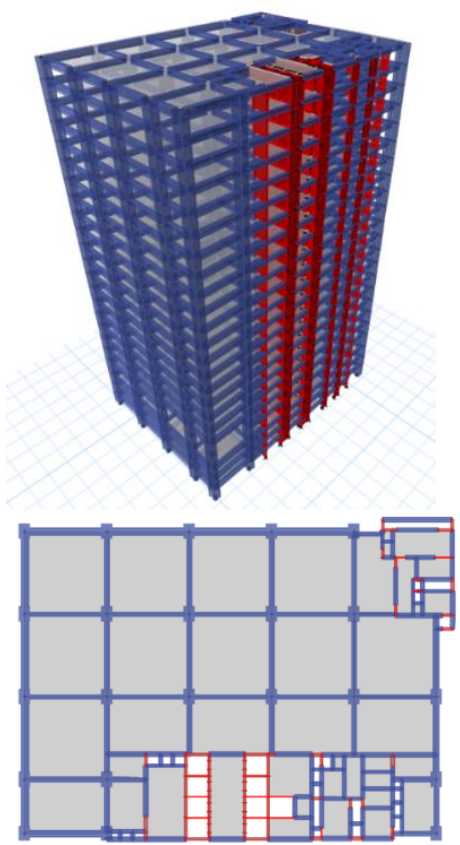

(Multi-storey tall structure with Conventional slab)

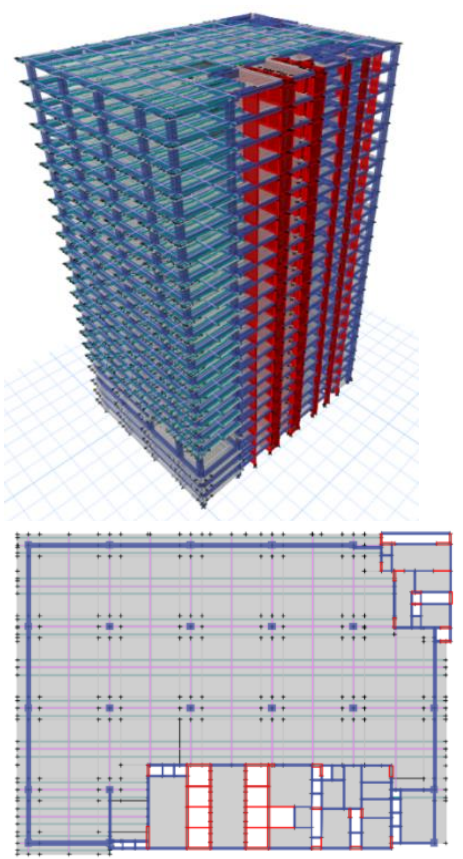

(Multi-storey tall structure with PT flat slab)

\section{MATERIALS \& PARAMETERS:-}

- $\quad$ Live Load - $4 \mathrm{KN} / \mathrm{M}^{2}$

- Super Dead Load - 3 KN/M ${ }^{2}$

- Concrete Grades:- Beams -M25 , Columns - M50 , Slabs - M25 (conventional) , Slabs - M35 (Posttensioned)

- Steel Grades:- Fe500 and Fe415

- Strand Area for PT slabs - $100 \mathrm{M}^{2}$

- Seismic parameters:- Response Reduction ( R ) - 3, Seismic Zone Factor ( Z ) - 0.1, Importance Factor $(\mathrm{I})-1, \mathrm{~T}=2.337$

\section{ANALYTICAL COMPARISION:-}

6.1 Graphs outputs of storey response in both types of slabs are below - 


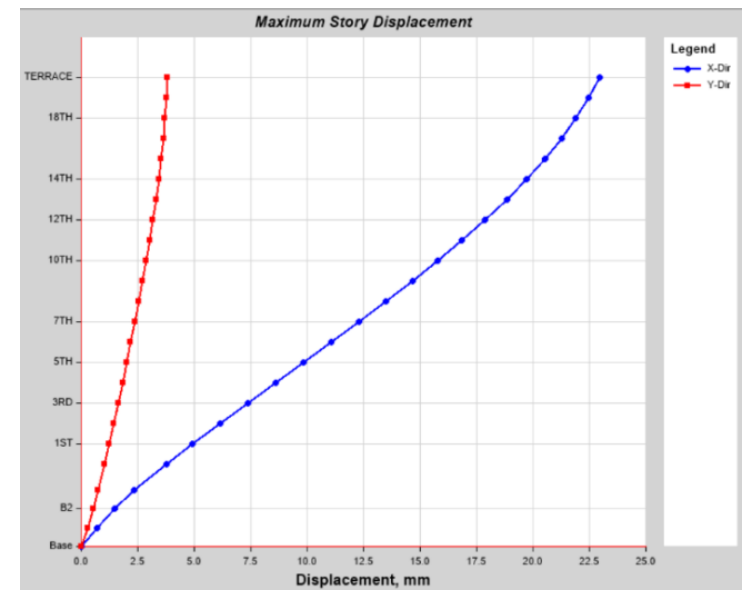

(Conventional slab - Seismic Storey Displacement in $\mathrm{X}$ dir.)

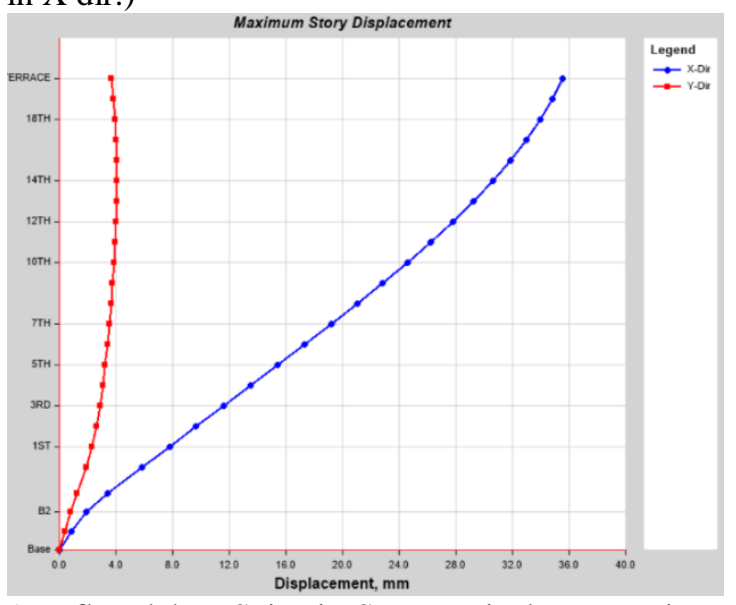

(PT flat slab - Seismic Storey Displacement in X dir.)

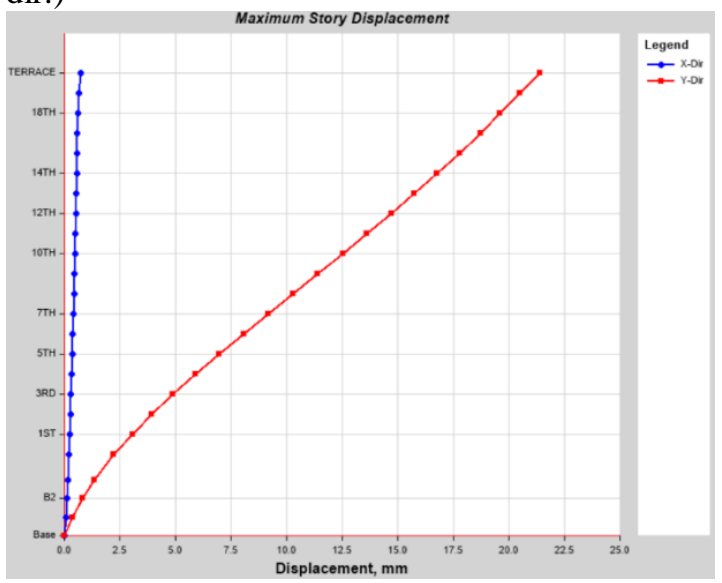

(Conventional slab - Seismic Storey Displacement in Y dir.)

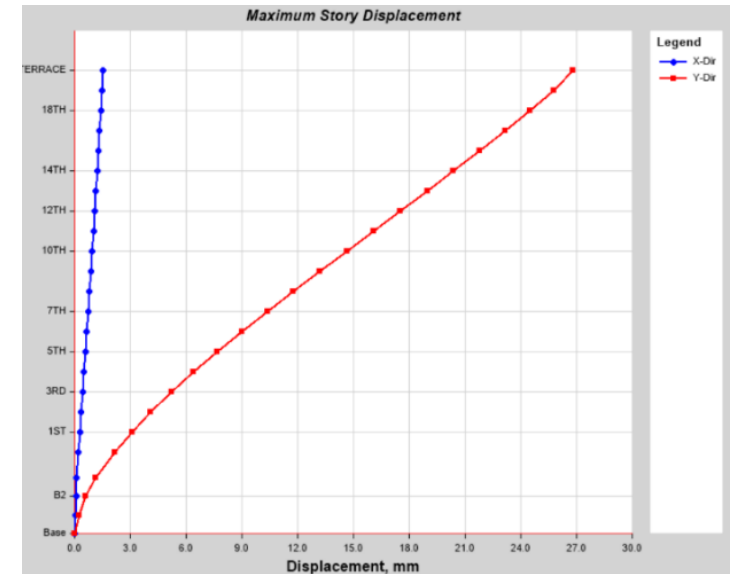

(PT flat slab - Seismic Storey Displacement in $\mathrm{Y}$ dir.)

\begin{tabular}{|c|c|c|}
\hline \multicolumn{2}{|c|}{ Maximum seismic storey displacement (mm) } \\
\hline & X- Direction & Y - Direction \\
\hline $\begin{array}{c}\text { Conventional } \\
\text { slab }\end{array}$ & 23 & 21 \\
\hline PT Flat slab & 35.5 & 27 \\
\hline
\end{tabular}

This result shows that PT Flat slab system have more storey displacement than normal conventional system as it is more flexible in case of seismic load. 6.2 Slab displacement with deformed slab due to Dead Load (DL) has been shown below -

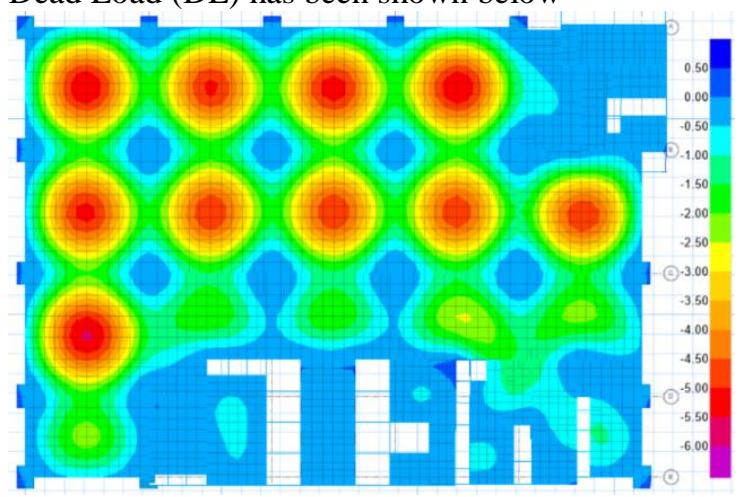

(Conventional slab - Displacement due to DL)

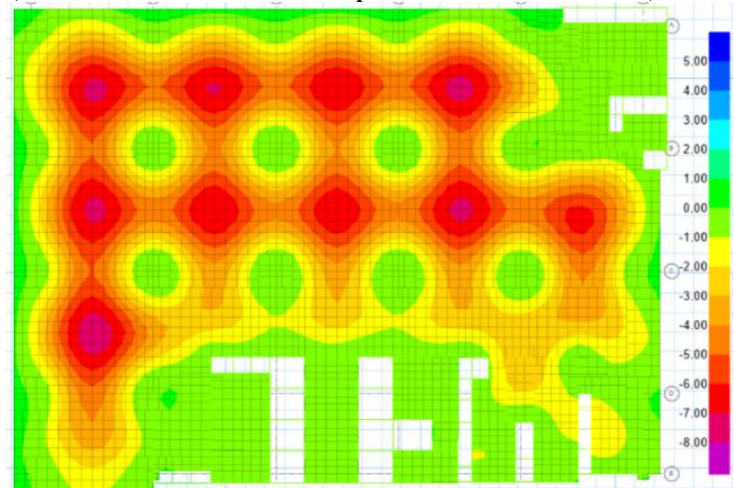

(Flat slab - Displacement due to DL) 


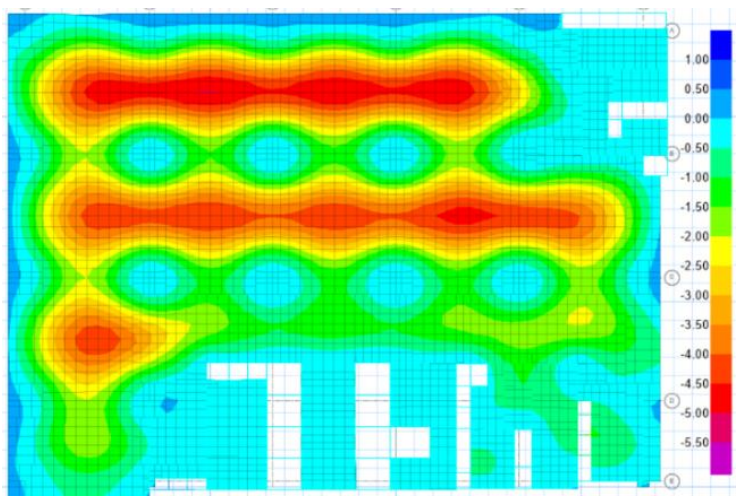

(PT-Flat slab - Displacement due to DL)

\begin{tabular}{|c|c|c|c|}
\hline & $\begin{array}{c}\text { Conventional } \\
\text { slab }\end{array}$ & $\begin{array}{c}\text { Flat } \\
\text { slab }\end{array}$ & $\begin{array}{c}\text { PT flat } \\
\text { slab }\end{array}$ \\
\hline $\begin{array}{c}\text { Max } \\
\text { displacement } \\
(\mathrm{mm})\end{array}$ & 5.63 & 7.75 & 5.03 \\
\hline
\end{tabular}

Even for load Combinations PT flat slab has lowest slab displacement.

I.e. Considering load combination (1.2xDL+1.6xLL+1.2xSDL)

\begin{tabular}{|c|c|c|c|}
\hline & $\begin{array}{c}\text { Conventional } \\
\text { slab }\end{array}$ & $\begin{array}{c}\text { Flat } \\
\text { slab }\end{array}$ & $\begin{array}{c}\text { PT flat } \\
\text { slab }\end{array}$ \\
\hline $\begin{array}{c}\text { Max } \\
\text { Displacement } \\
(\mathrm{mm})\end{array}$ & 15.61 & 22.2 & 14.51 \\
\hline
\end{tabular}

In case of slab displacement normal flat slab result more in magnitude but it is applied with post tensioned tendons that gives even lesser displacement than conventional.

PT flat slab have around 7\%-10\% lesser slab displacement than conventional slab.

6.3 Following are the calculated Reaction force on column due to slab DL -

Taking 3 column grids as to compare reaction force.

\begin{tabular}{|c|c|c|}
\hline \multicolumn{3}{|c|}{$\begin{array}{c}\text { CONVENTIONAL SLAB } \\
\text { Column Reaction Force }(\mathrm{KN})\end{array}$} \\
\hline Grid 1 & Grid 2 & Grid 3 \\
\hline 1018.34 & 1017.63 & 738.5 \\
\hline 1258.61 & 1341.17 & 1020.91 \\
\hline 1214.89 & 1285.96 & 1013.97 \\
\hline 1216.52 & 1292.47 & 1026.27 \\
\hline 1262.7 & 1144.47 & 812.451 \\
\hline
\end{tabular}

\begin{tabular}{|c|c|c|}
\hline \multicolumn{3}{|c|}{ FLAT SLAB } \\
Column Reaction Force $(\mathrm{KN})$ \\
\hline Grid 1 & Grid 2 & Grid 3 \\
\hline 729.13 & 740.45 & 529.34 \\
\hline 834.88 & 872.81 & 738.01 \\
\hline 777.39 & 881.92 & 713.01 \\
\hline 780.81 & 889.28 & 730.99 \\
\hline 795.32 & 724.59 & 545.5 \\
\hline
\end{tabular}

\begin{tabular}{|c|c|c|}
\hline \multicolumn{3}{|c|}{ PT FLAT SLAB } \\
\hline Column Reaction Force (KN) \\
\hline 719.5 & 735.81 & Grid 3 \\
\hline 846.56 & 884.55 & 758.96 \\
\hline 778.66 & 879.37 & 707.31 \\
\hline 784.92 & 895.11 & 743.65 \\
\hline 800.81 & 728.3 & 528.37 \\
\hline
\end{tabular}

Reaction forces acting on columns are also lesser in case of PT flat slab and magnitude is almost equal to normal flat slab.

The percentage of decreased magnitude in between PT flat and conventional is around $25 \%$ to $31 \%$. So taking the decreased reaction force as $28 \%$.

6.4 Following are the calculated slab forces due to DL-

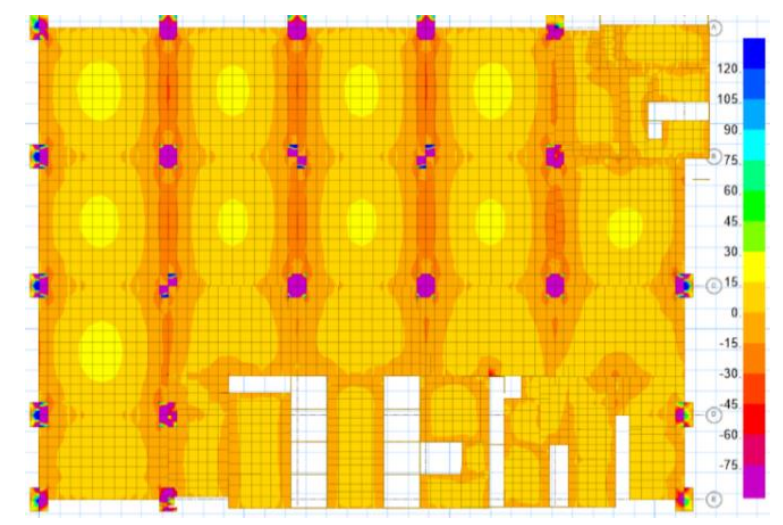

(Conventional slab - slab forces due to DL) 


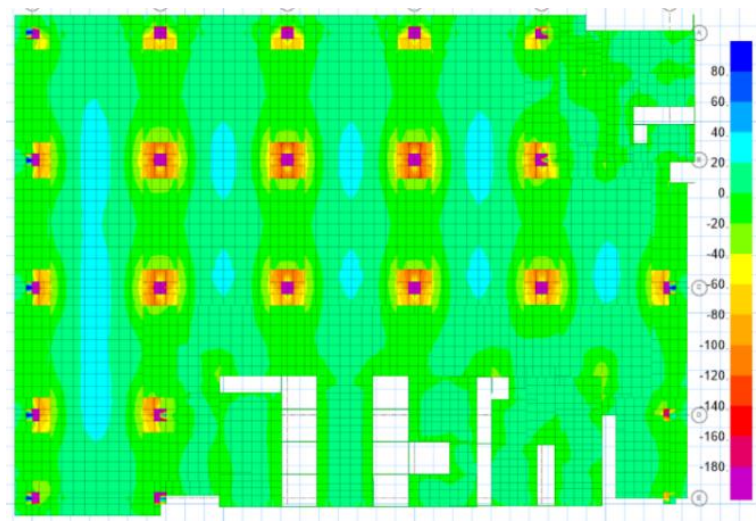

(Flat slab - slab forces due to DL)

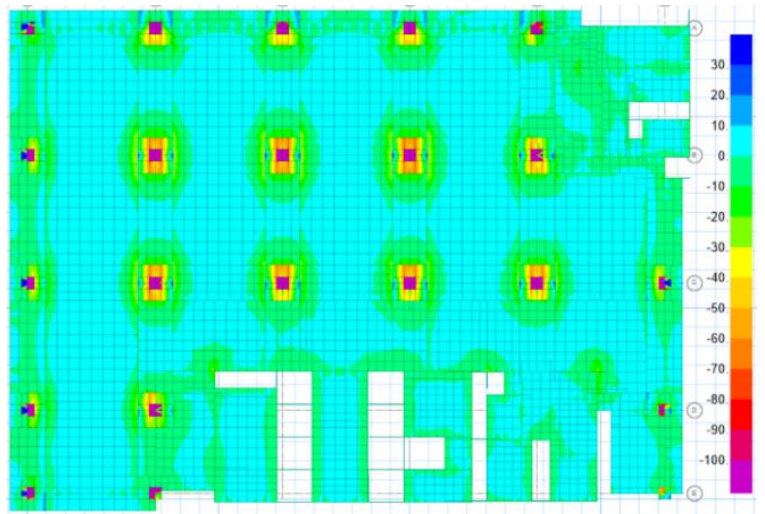

(PT Flat slab - slab forces due to DL)

\begin{tabular}{|c|c|c|}
\hline \multicolumn{3}{|c|}{$\begin{array}{c}\text { CONVENTIONAL SLAB } \\
\text { Forces ( KN.M/M) }\end{array}$} \\
\hline MAX & MIN & AVG \\
\hline 18.97 & 16.76 & 17.865 \\
\hline
\end{tabular}

\begin{tabular}{|c|c|c|}
\hline \multicolumn{3}{|c|}{ FLAT SLAB } \\
Forces ( KN.M/M) \\
\hline MAX & MIN & AVG \\
\hline 22.69 & 16.28 & 19.485 \\
\hline
\end{tabular}

\begin{tabular}{|c|c|c|}
\hline \multicolumn{3}{|c|}{ PT FLAT SLAB } \\
Forces ( KN.M/M) \\
\hline MAX & MIN & AVG \\
\hline 9.43 & 5.5 & 7.465 \\
\hline
\end{tabular}

Here, Slab forces in 3 cases shows that PT flat slab have much less magnitude than other 2 types of slab systems.

And it is decreased by around $58 \%$ as per calculation but taking it as whole $60 \%$ as a result.

\section{DESIGN COMPARISON:-}

7.1 Slab designing of these 3 types slabs are shown and compared -

Considering a strip of slab for design consideration and area of steel has been calculated for different types of slab.

\section{Moment Diagram (kN-m)}

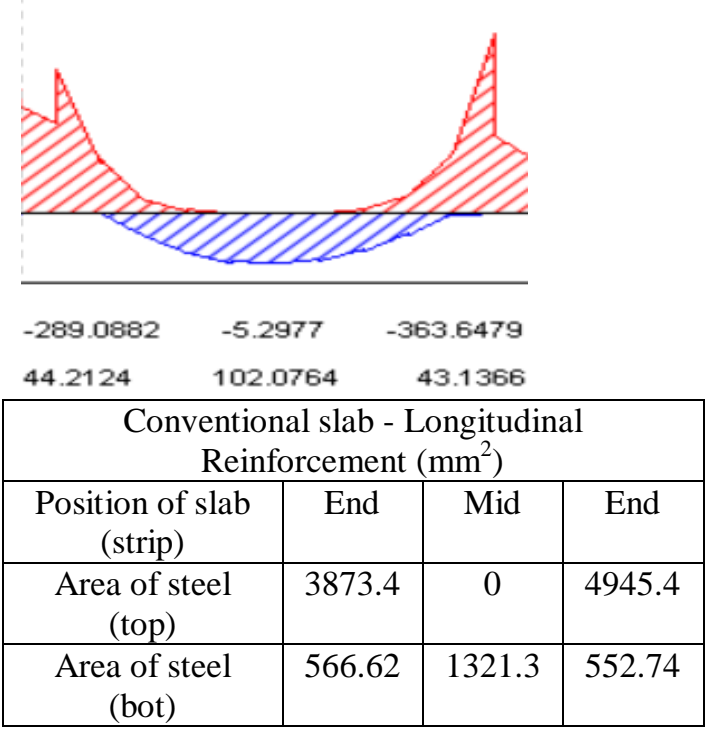

\section{Moment Diagram (kN-m)}

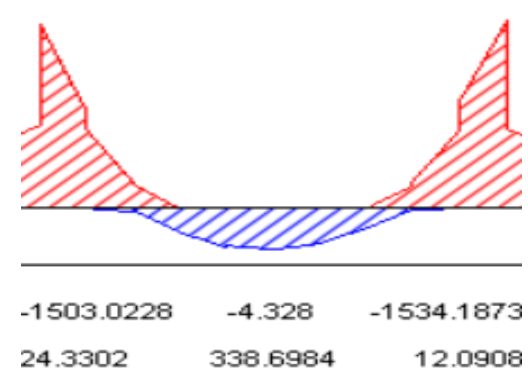

\begin{tabular}{|c|c|c|c|}
\hline \multicolumn{4}{|c|}{ Flat slab - Longitudinal Reinforcement $\left(\mathrm{mm}^{2}\right)$} \\
\hline $\begin{array}{c}\text { Position of slab } \\
\text { (strip) }\end{array}$ & End & Mid & End \\
\hline $\begin{array}{l}\text { Area of steel } \\
\text { (top) }\end{array}$ & 11302 & 0 & 10203 \\
\hline $\begin{array}{l}\text { Area of steel } \\
\text { (bot) }\end{array}$ & 310.4 & 4497.3 & 195.96 \\
\hline
\end{tabular}

\section{Moment Diagram (kN-m)}

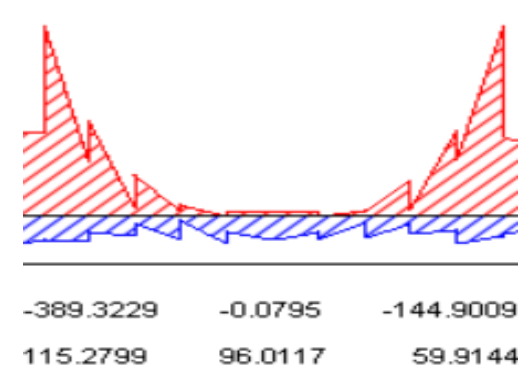


International Journal of Research in Advent Technology, Vol.7, No.5, May 2019 E-ISSN: 2321-9637

Available online at www.ijrat.org

\begin{tabular}{|c|c|c|c|}
\hline \multicolumn{3}{|c|}{ PT Flat slat - Longitudinal Reinforcement $\left(\mathrm{mm}^{2}\right)$} \\
\hline $\begin{array}{c}\text { Position of slab } \\
\text { (strip) }\end{array}$ & End & Mid & End \\
\hline $\begin{array}{c}\text { Area of steel } \\
\text { (top) }\end{array}$ & 46.8 & 2059.5 & 0 \\
\hline $\begin{array}{c}\text { Area of steel } \\
\text { (bot) }\end{array}$ & 1070 & 0 & 321.53 \\
\hline
\end{tabular}

These moment diagram and area of steel shows that normal flat slab have much more reinforcement required in slab design than conventional. But if Flat slab is Post tensioned then reinforcement (Area of steel) also decreases crucially and the manner of reinforcement pattern of end-mid-end also changes as we using PT tendons to this system.

7.2 Another main thing of designing between these 2 types of systems i.e. PT flat and conventional is, the column and beam sizes which are used in PT flat system can't be considered in conventional. As the system will not sustain and have to increase the dimension of structure sections.

Example :-

Taking a beam or column section and comparing its cross sectional area -

\begin{tabular}{|c|c|c|}
\hline $\begin{array}{c}\text { Type of } \\
\text { system }\end{array}$ & Dimension $(\mathrm{mm})$ & $\begin{array}{c}\text { Sectional } \\
\text { Area }\left(\mathrm{mm}^{2}\right)\end{array}$ \\
\hline PT flat slab & $600 \times 900$ & 540000 \\
\hline $\begin{array}{c}\text { Conventional } \\
\text { slab }\end{array}$ & $900 \times 1200$ & 1080000 \\
\hline
\end{tabular}

So, here sectional area of a perimeter beam of PT flat slab and edge beam of conventional slab has been shown.

Also we can clearly see the difference in dimension of section as well as the cross sectional area.

Conventional system is not sustainable this dimension as PT flat because of long span like $11 \mathrm{~m}$ which is too high for beam column frame structure and it leads to increase in dimension.

Approximately, the sectional area increases for conventional is $50 \%$.

\section{QUANTITY AND ECONOMICAL COMPARISON}

Conventional slab system steel quantities calculated below and compared -

SLAB STEEL QUANTITY

(CONVENTIONAL SLAB)

\begin{tabular}{|l|ll|l|l|}
\hline $\begin{array}{l}\text { SR } \\
\text { NO }\end{array}$ & $\begin{array}{l}\text { Bar } \\
(\mathrm{mm})\end{array}$ & Size & $\begin{array}{l}\text { Length } \\
(\mathrm{m})\end{array}$ & Weight $(\mathrm{kg})$ \\
\hline 1 & 10 & & 1011.44 & 623.2 \\
\hline
\end{tabular}

\begin{tabular}{|l|l|l|l|}
\hline 2 & 12 & 9544.5 & 8472.91 \\
\hline 3 & 14 & 379.92 & 458.92 \\
\hline 4 & 16 & 7664.12 & 12097.39 \\
\hline 5 & 18 & 4087.66 & 8165.44 \\
\hline 6 & 25 & 1166.04 & 4492.85 \\
\hline 7 & Total & - & $34,310.71$ \\
\hline
\end{tabular}

SLAB STEEL QUANTITY

(PT FLAT SLAB)

\begin{tabular}{|l|l|l|l|}
\hline $\begin{array}{l}\text { SR } \\
\text { NO }\end{array}$ & Bar Size $(\mathrm{mm})$ & Length $(\mathrm{m})$ & Weight $(\mathrm{kg})$ \\
\hline 1 & 10 & 594.26 & 366.16 \\
\hline 2 & 12 & 7611.62 & 6757.06 \\
\hline 3 & 14 & 753.64 & 910.36 \\
\hline 4 & 16 & 6721.56 & 10609.6 \\
\hline 5 & 18 & 2671.2 & 5335.93 \\
\hline 6 & 25 & 400.52 & 1543.22 \\
\hline 7 & Total & - & $25,522.32$ \\
\hline
\end{tabular}

From the above 2 tables we can see that the steel requirement for the slab in case of PT flat slab is less than the conventional system.

The decreased in quantity is approximately $25 \%$ of steel.

On the other hand, the PT flat slab systems do not require internal beams i.e. beam column frame structures. As slab in this system only supported by the column capitals or drop panels. Only perimeter beams are provided in this type of system. So basically the quantity for beam steel and concrete also decreases as compared to conventional system.

Considering the area of sections in both types of slab systems, result shows 50\% increase in sectional area which leads to increase in concrete and steel quantity. It result costlier than PT flat system.

\section{CONCLUSION:-}

From all of the above results and comparison of different types of slab systems, here are some conclusive points described below -

- PT flat slab system has greater flexibility than conventional system due to more quantity of story displacement in case of seismic analysis but in PT flat slab perimeter beams are provided to maintain the structure from earthquake load.

- Normal flat slab results in more magnitude of slab displacement than conventional slab but the post-tensioned flat slab results $7 \%-10 \%$ lesser slab displacement than the conventional system. 


\section{International Journal of Research in Advent Technology, Vol.7, No.5, May 2019 E-ISSN: 2321-9637 \\ Available online at www.ijrat.org}

- Flat slab and PT flat slab system have an equal reaction force on columns and $28 \%$ lesser than the conventional system.

- Considering slab forces, PT flat slab results in almost $60 \%$ lesser force than compared to the normal conventional slab. Normal flat results even more force than a normal slab.

- Bending moment diagram shows between these 3 types of slab system, Flat slab has a more bending moment than the other two and PT flat slab have least among all system. Due to this the area of steel for slab design is also less and its orientation is different because of post-tensioned tendons.

- As per the structural design of both, dimensions of structural members required to be more in case of the beam-column conventional system as its inefficient in case of long spans as compared to PT flat slab system. Story to story height gets clumsy or lack of story height due to bigger structural members.

- The economic overview is also necessary to be compared. Slab steel quantity in PT slab gets decreased by $25 \%$ as compared to the conventional slab. Also, no of beams are less in the flat slab or PT flat slab ie only perimeter beams provided.

- If the same model is presented with PT flat slab and conventional slab then the sectional are of structural members will be more by $50 \%$ which will lead to an uneconomical structure.

From the above points and reasons, we can clearly conclude PT flat slab better than conventional for many reasons.

\section{REFERENCE:-}

[1]. Anusha. I. Koti, Dr. S. B. Vanakudre , "Analysis of PT flat slab with DropConsidering Seismic Effect" International Research Journal of Engineering and Technology, Volume: 05 Issue: 06 | June-2018
[2]. Kamal Padhiar, Dr. C.D. Modhera, Dr. A. K. Desai, "Comparative Parametric Study For Post-Tension Flat Slab And Flat Slab With Drop System" International Journal of Civil Engineering and Technology, Volume 8, Issue 5, May 2017

[3]. Boskey Bahoria, Prof.R. S. Deotale ,Dr D K Parbat, "Comparative Design of RCC \& Posttensioned flat slabs" Research Gate, 09-11 DECEMBER, 2010

[4]. Boskey Vishal Bahoria, Dhananjay K. Parbat, "Analysis and Design of RCC and Posttensioned Flat Slabs Considering Seismic Effect" International Journal of Engineering and Technology, Vol. 5, No. 1, February 2013

[5]. Shriraj S. Malvade, P.J. Salunke, "Analysis of Post-Tensioned Flat Slab by using SAFE" International Journal of Scientific Engineering and Applied Science,Volume-3, Issue-3, March 2017

[6]. Amrut Manvi, Sandeep Gouripur, Pooja Sambrekar, Ramanjeet kaur, Dr. Kishor S. Kulkurni, "Cost Comparison Between Conventional And Flat Slab Structures", International Research Journal of Engineering and Technology, Volume: 02 Issue: 03 | June2015

[7]. Rahul P. Kikanil, Kishan N, Davara, Yati R.Tank, Palak V.Trivedi, Bhavin Sheladiya, "A Comparative Review On Behavioural Aspect Of Posttensioning Voided Flat Slab With Other Slab Systems", International Journal of Advance Engineering and Research Development Volume 4, Issue 11, November 2017

[8]. Mohana H.S, Kavan M.R, "Comparative Study of Flat Slab and Conventional Slab Structure Using ETABS for Different Earthquake Zones of India" International Research Journal of Engineering and Technology, Volume: 02 Issue: 03 | June-2015 